\title{
Glycogen storage disease due to liver and muscle phosphorylase kinase deficiency
}

INSERM

\section{Source}

INSERM. (1999). Orphanet: an online rare disease and orphan drug data base. Glycogen storage disease due to liver and muscle phosphorylase kinase deficiency. ORPHA:79240

Glycogen storage disease (GSD) due to liver and muscle phosphorylase kinase (PhK) deficiency is a benign inborn error of glycogen metabolism. It is the mildest form of GSD due to PhK deficiency (see this term). 